\title{
Mulemba
}

Revista Angolana de Ciências Sociais

4 (8) | 2014

Globalização, gestão e dinâmicas de desenvolvimento regional e local

\section{Mundombe do «Dombe» ou Ndombe do Mundombe?...}

Mundombe of «Dombe» or Ndombe of Mundombe?...

\section{Armindo Jaime Gomes}

\section{(2) OpenEdition Journals}

Edição electrónica

URL: http://journals.openedition.org/mulemba/401

DOI: $10.4000 /$ mulemba.401

ISSN: 2520-0305

Editora

Edições Pedago

\section{Edição impressa}

Data de publição: 1 novembro 2014

Paginação: 77-100

ISSN: 2182-6471

\section{Refêrencia eletrónica}

Armindo Jaime Gomes, «Mundombe do «Dombe» ou Ndombe do Mundombe?...», Mulemba [Online], 4 (8) | 2014, posto online no dia 21 novembro 2016, consultado o 26 janeiro 2021. URL: http:// journals.openedition.org/mulemba/401 ; DOI: https://doi.org/10.4000/mulemba.401

Este documento foi criado de forma automática no dia 26 janeiro 2021.

Tous droits réservés 


\title{
Mundombe do «Dombe» ou Ndombe do Mundombe?...
}

Mundombe of «Dombe» or Ndombe of Mundombe?...

\author{
Armindo Jaime Gomes
}

\section{NOTA DO EDITOR}

Artigo solicitado ao Autor

Recepção do manuscrito: 30/10/2014

Conclusão da revisão: 20/12/2014

Aceite para publicação: 30/12/2014

\section{Introdução}

1 Desde os tempos mais remotos, o litoral centro-sul de Angola, num contexto geográfico característico ao que são hoje as províncias de Benguela e do Namibe, conheceu um processo de povoamento bastante complexo, num vasto território marcado sobretudo por deserto e aridez, numa extensa faixa marítima. Distintas comunidades, inicialmente com afinidades e características nómadas dos Vahelelo, se foram dispersando pelo deserto e estepes, distribuídos entre Vandombe, ${ }^{1}$ Vakuvale e demais comunidades, nomeadamente os Vacyavikwa, ${ }^{2}$ Vangendelengo, Vahinga, Vandimba, Vakwanyoka, subgrupos de maior extensão, muitas vezes designados «Curocas», um têrmino por que ficaram mais conhecidos na literatura etnográfica colonial (GRAÇAS 1948), em função da localidade geográfica onde tradicionalmente se encontram, sendo confundidos, por isso, com os Vakuvale e Vakwanyoka.

2 Tratam-se de comunidades diversamente ocupadas, seja em agricultura de subsistência, pastorícia, caça ou pesca. Quanto à classificação etnolinguística, parece-nos que é de contrariar a tese de alguns estudiosos que acerca delas escreveram ainda na época colonial, tais como Augusto Bastos (1902), Norberto Gonzaga (1963), Mesquitela Lima 
(1964), José Redinha (1961, 1970, 1973, 1975), escritos esses defendidos algumas vezes por alguns estudiosos angolanos segundo a qual os Vandombe são parte integrante do grupo etnolinguístico umbundu.

Uma vez que inúmeras constatações observadas no terreno apontam precisamente o contrário, é partindo desse pressuposto que, no geral, se fixa o presente estudo. Para tal, foram feitas algumas incursões de campo, num período de tempo relativamente curto, que compreendeu os anos de 1997 a 2007, mas, mais intensamente entre os anos 2000 e 2002, altura da nossa fixação na comuna do Dombe-Grande, ao serviço de um operador não estatal, com base nos métodos de processos de desenvolvimento comunitário com destaque para os históricos, sociológicos e antropológicos.

\section{Do Ndombe ao Dombe-Grande}

Das constatações locais atrás aludidas, começamos por procurar estabelecer uma relação, quer do ponto de vista antroponímico e etnonímico, quer toponímico entre o Mundombe em particular, e o Dombe-Grande, em geral. Ambos os falantes dominam predominantemente a língua umbundu, uma língua muito dinâmica e historicamente expansionista, fomentada no Planalto Central de Angola, com visível implantação ao longo da faixa litorânea do Atlântico centro-sul, incluindo a região em referência. Daí que determinados estudiosos na época colonial tenham concluído que os Vandombe eram parte integrante do grupo etnolinguístico umbundu, pois, na realidade, a população predominante do Dombe-Grande ou é umbundu, ou apenas desta língua os seus habitantes têm maior preferência, porque dela obtêm maior utilidade.

Como se pode depreender, os estudiosos acima citados, ao classificarem os povos encontrados, argumentaram mais a favor do factor língua ouvida, sem o devido domínio - em determinadas circunstâncias, com o apoio de intérpretes com fraco domínio da língua portuguesa - , sem os métodos de pesquisa adequados, e, muitas vezes, com tendências pouco claras. A língua umbundu que, geralmente, o Mundombe fala, é característica de quem tem a sua própria língua materna. Num passado muito próximo, como todos as comunidades distribuídas em torno do complexo sociocultural umbundu - referimo-nos ao Planalto Central de Angola e seu hinterland ou periferia -, o Mundombe foi um excelente conservador da sua língua materna - o olundombe -, não obstante comunicar-se em umbundu, pois, em primeiro lugar, o meio social Ndombe é desde há muito tempo comunicável através dessa língua, pautando-se em segundo lugar a língua portuguesa, acabando assim a língua olundombe por ficar entre os falantes minoritários, sendo por isso, possivelmente, apenas utilizada nos contextos mais localizados, nomeadamente no âmbito da organização social, residencial, e mais fechados ainda, no âmbito da família nuclear. Os indicadores que estabelecem o quadro das diferenças registam-se particularmente na linguagem corrente em relação aos conceitos socio-antropológicos, sobretudo culturais, que têm a ver com as diversas instituições culturais endógenas.

Os fenómenos socioculturais pouco vulgares, ou aqueles que encontram designações apropriadas na língua umbundu, diferem, já que, passam reflexivamente para o léxico olundombe, a língua materna que caracteriza a cultura dos Vandombe e isso sem interpretação literal. Falamos dos rituais de passagem: nascimento, Ohovya (GOMES 2007); puberdade, Ekwenje (DUFF 1945; GOMES 2007) e okufekãla (ESTERMANN 1944; MELO 1990; GOMES 2007); relativo à morte, Okuyanga (GOMES 2007); além da ekula, 
instituição congregadora realizável em cada 25 anos entre as comunidades Vandombe cujas referências fizemos eco em publicações anteriores. ${ }^{3}$ A pastorícia, apesar de ser uma das actividades fundamentais que coloca o Mundombe como pastor de grande envergadura histórica, no entanto, durante a implantação do sistema colonial essa actividade de tradição foi praticamente ignorada, tendo sido favorecida a agricultura resultante do sistema colonial imposto pela Companhia Assucareira de Angola (sic); no entanto, é necessário deixar bem claro que o modus vivendi mundombe gira em torno do touro, o que, até certo ponto, o associa ou aproxima do universo helelo, facto mais do que suficiente para não ser incluído na sociocultura umbundu, que é essencialmente fundamentada em torno da terra e da agricultura.

7 No seu contexto etnogeográfico, o Mundombe interage a volta de dois universos: por um lado, o repartido entre os umbundu (FELNER 1940), interpretado pela realidade sociocultural dos subgrupos etnolinguísticos Vacisanji, Vambokoyo e Vahañya; e, por outro lado, o dos Vacilenge, ${ }^{4}$ por este confundido em virtude das suas afinidades com os Vankhumbi. É partindo desta realidade, que os etnólogos Charles Estermann (1951), Mesquitela Lima (1964), José Redinha (1970), e outros estudiosos acima referidos, pretenderam qualificar o status socio-antropológico Ndombe numa altura em que:

a. a língua olundombe era entenda como um dialecto cruzado entre as línguas umbundu e olucilenge; 5

b. os antropónimos, topónimos, etnónimos, zoónimos e demais elementos «estranhos» dentro da língua umbundu falada pelo Mundombe eram pertença do olundombe;

c. ou ainda, os elementos que não fazem parte da língua umbundu, mas que são característicos na cultura ndombe, eram de origem cilenge. ${ }^{6}$

8 As hipóteses aqui aludidas resultam das constatações a elas contrárias, tal como ilustra correctamente a etnóloga angolana Ana de Sousa Santos (1963; 1965), e advogada por Ruy Duarte de Carvalho (1997), que soube apresentar testemunhos válidos e convincentes acerca da comparação do Mundombe com o Mukuvale, contrariando assim José Redinha (op. cit.) e os seus fiéis seguidores; tais posicionamentos, contribuíram positiva e claramente para as conclusões a que chegamos com as recolhas efectuadas no terreno na década de 1997-2007, já anteriormente aludida. Ouvindo a fala do Mundombe, a interpretação assumida é de que outrora teve, e tem ainda hoje, uma língua própria, que sendo paralela ao umbundu e olucilenge ${ }^{8}$ resiste, sem que para tal percamos de vista a linha de parentesco que geralmente é observada na fala regional de origem e pertença Bantu.

9 Se ao qualificar os grupos etnolinguísticos locais, os estudiosos atrás apontados se tivessem baseado na linguística comparada Bantu (cf. ESTERMANN 1960) - não obstante a dimensão do trabalho etnográfico em Angola tenha crescido com a criação de instituições afins, tais como o Instituto de Investigação Científica de Angola (IICA) e o Centro de Informação e Turismo de Angola (CITA), este último apoiado pelo Fundo de Turismo e Publicidade de Angola (FTPA) -, poderiam ter chegado possivelmente a outras conclusões, pelo que se depreende que o universo teórico tanto antropológico, quanto histórico dos estudiosos em referência, se manteve distanciado do conhecimento da realidade local (GOMES 2007). O presente argumento parte do princípio segundo a qual, por si só, o estudo da língua não nos parece o factor determinante para a qualificação de qualquer grupo etnolinguístico no contexto Bantu (ELIOT 1965). Entende-se que, a par da língua, há que contar com os hábitos, os usos e costumes, a religiosidade e a modalidade psíquica, a história e a consciência de 
pertença (RIBAS 1977), que juntos poderão constituir factores determinantes para se chegar a essa qualificação.

O Mundombe não se assume com qualquer outra realidade sociocultural (MANZAMBI 1993: 16). Não é Cimbundu ${ }^{9}$ nem Cilenge. ${ }^{10}$ É Ndombe por ter consciência de não ser aqueles (ALTUNA 1993). Aceita e prefere ser Ndombe «puro», de «origem», com descendência Ngendelengo, Mbundya, Kwandu, Mbali ou de outras que na qualificação de Charles Estermann (1949) e José Redinha (1973), são ligadas aos Vahelelo.

11 Ao aceitar a descendência Ngendelengo, o Mundombe passa a contribuir para as conclusões de Ana de Sousa Santos (op. cit.), secundada por Ruy Duarte de Carvalho (op. cit.), como fazendo parte do grupo etnolinguístico pastoril Helelo, mais conhecido por Ovihelelo (singular: Cihelelo), sobejamente marcada pelos Vakuvale, bastante distinguidos entre os demais (DINIZ 1915), historicamente localizados para além do litoral sul do Dombe-Grande (DELGADO 1948), mormente no ângulo sudoeste de Angola.

12 Para entender a etimologia do designativo Helelo (plural: Ovihelelo), o Padre Albino Alves refere que esse termo vem do étimo hela do verbo okuhela, o que em língua portuguesa significa «agitar, menear, brandir, fazer vibrar a azagaia» (ALVES 1951). Uma outra interpretação corresponde ao do verbo okuhalela em olundombe ou okukalela do verbo okukala em umbundu, querendo dizer, «estar, ficar» em português (op. cit.), dito em outras vertentes linguísticas locais, o mesmo que «decidir ficar», ou, simplesmente, «gritar, urrar, alegrar-se». Acontece, porém, que as zonas baixas em relação ao planalto são conhecidas por helelo.

13 Além da ancestralidade (ELIADE 2006) assumida por cada subgrupo do grupo etnolinguístico Ovihelelo, razão do reflexo etnonímico ao espírito totémico (REDINHA 1970), de modo geral, à excepção dos Vandombe, e até certo ponto dos Vakuvale, as comunidades helelo caracterizam-se por um profundo sentimento de pertença e de endogamia de grupo (ALTUNA 1993), ao ponto de não admitirem cruzamentos com membros de outros grupos etnolinguísticos (ESTERMANN 1951). Embora não sendo muito convencidos como os Vandombe, «nutrem elevado etno-desprezo pelos vizinhos» (NOGUEIRA s.d., 1885, 1877) e as manifestações xenofóbicas (ESTERMANN 1960) que lhes têm sido característicos, constituíram razão suficiente para os históricos conflitos contra os expedicionários europeus mas também contra os Ovimbundu, para os quais atribuem o designativo de Vanano (singular: Munano), ${ }^{11}$ querendo dizer "os planálticos, atrasados, incivilizados, salteadores de gado».

Posto no Dombe-Grande em 1994, sendo a primeira vez para um estudo comparativo dos vários tipos Mbali (CARDOSO 1963) existentes ao longo do litoral centro-sul de Angola, ${ }^{12}$ à luz da série de publicações de Carlos Lopes Cardoso $(1963,1966)$, não foi difícil perceber que ao Mundombe subsistiam algumas discordâncias com o Ocimbundu, ${ }^{13}$ fundamentalmente partindo do porte externo à manutenção estética (NETO 1994, 1997). A primeira ideia captada era de que aquele estava mais próximo dos povos litorâneos ao sul do Dombe-Grande, seguido pela Lucira, ${ }^{14}$ Camucuio, ${ }^{15}$ Bibala ${ }^{16}$ ao Tombwa, sem confundir com outros aglomerados ou povoacões de origem não-Bantu (ESTERMANN 1951a), no caso das variantes Vatwa. O problema que se pode levantar consiste na confusão da língua e do porte externo com os tipos Ovimbundu do DombeGrande, de origem mbokoyo, mbalombo, hañya influentes na área sociocultural Ndombe. De recordar que até à penetração do mercantilismo europeu na região (FELNER 1940), cuja introdução não foi simultânea em toda Angola (LEMOS 1929; 1932), 
a diferenciação no parentesco da identidade cultural (NETO 1992-1993) de origem Bantu apresenta-se muito pequenina, milimétrica (MANZAMBI 1993).

Discussão aturada sobre as estruturas e o funcionamento de instituições de carácter sociocultural Ndombe (GOMES 2007), sem delimitações estanques, pode contribuir sobremaneira para a dissipação da confusão ora aludida, desde que se parta do princípio segundo a qual Ndombe e Mundombe são dois valores diferentes num único semelhante: Ndombe refere-se ao complexo cultural do Mundombe do Dombe-Grande, logo, Ndombe é Dombe-Grande mas o Dombe-Grande não é necessariamente Mundombe.

\section{Extensão e compreensão toponímica}

Como é sabido, o actual núcleo sociocultural Ndombe está confinado a volta da foz do rio Kupololo; no entanto, a história pré-colonial de Angola descreve o seu espaço de influência na região limitada pelos rios Catumbela, ${ }^{17}$ Bero, ${ }^{18}$ Giraúl $^{19}$ e Bentiaba ${ }^{20}$ (DELGADO 1944), área onde geralmente estão localizados outros subgrupos Helelo (GOMES 2007). Nesta ordem de ideias repartem o espaço entre si, embora predominando o litoral centro-sul (FELNER 1940), área compreendida entre os rios Katombela $^{21}$ e Kuneni ${ }^{22}$ (GOMES 2007). Fizemos menção às descrições de autores que na época colonial trabalharam sobre esta região e povos, tal como demonstra M. J. de Mendonça Torres (1950) e Ralph Delgado (1944), quando fazem referências sobre estas comunidades aglomeradas em pequenas povoações na Cipôla ${ }^{23}$ do soma Musungu (TORRES 1950), pertencente aos Vakuvale, local este que correspondia ao desaparecido «bairro da Nação» ${ }^{24}$ e aos Vandombe do Citôto ${ }^{25}$ (TORRES 1950), junto do actual Saco $\mathrm{Mar}^{26}$ onde, segundo o autor acima referenciado, «um terço destes Vandombe, - escrevia Lapa e Faro -, são possuidores de gado de que andam errantes em busca de pasto» (TORRES 1950). Nesta descrição, anterior ao processo colonial, o Mundombe aparece como um aglomerado capitalizando-se ao longo do litoral centro-sul até então, tal como acerca disso realça Delgado (1944) e Felner (1940); no entanto, o etnónimo não tinha equivalência ao topónimo que vigora nos nossos dias, fazendo entender que o Dombe «Grande» e o Ndombe do Mundombe eram originalmente distintos.

Em torno da problemática da origem do topónimo «Dombe "Grande"», poderão ser apresentadas inúmeras hipóteses:

a. durante a colonização portuguesa chamou-se «Dombe "Grande"» ao posto administrativo no distrito de Benguela e concelho da Baía Farta em Angola (MILHEIROS 1972);

b. até ao fim do sistema colonial, Dombe sem o «Grande», apareceu com a mesma categoria em Moçambique, na região de Manica, próximo da Beira; ${ }^{27}$

c. Um pequeno país da Borgonha reunida à coroa da França, na segunda metade do século XVIII, chamou-se Dombe(s) ou melhor, Principado de Dombes (Id., ibidem);

d. Tal como ocorreu por toda Angola, antes da colonização efectiva os portugueses cartografaram uma toponímia distinta do real, muitas vezes deturpada, pelo que a área sociocultural Ndombe não terá escapado a essa promiscuidade e passou a chamar-se «DombeGrande da Kizamba» (DELGADO 1944).

18 Apesar de haver referências bibliográficas sobre Kizamba, «Quizamba» ou «Quisamba», segundo Alexandra Aparício (1994), a origem e significação toponímica de Kizamba, para a localidade chamar-se «Dombe-Grande da Kizamba», não são localizáveis na região em referência, por não fazer parte do léxico dos povos ao sul do rio Longa, senão 
pronunciável entre as falas do corredor do rio Kwanza ao norte como já anteriormente havíamos constatado (GOMES 2007):

a. em línguas planálticas ao sul de Angola a pronúncia «Ki» de «Kizamba» e a escrita «Qui», para o mesmo som, não existem salvo o «Ci», na escrita missionária protestante ou«Tchi», no texto formal missionário católico;

b. tal como os sinais «r, q, ç», no léxico da região em epígrafe não se pratica o sinal «z» de «Kizamba» por não existir o referido som, senão o «S» fazendo a vez do «ç»;

c. nesta lógica, sendo de origem local «Kizamba» seria dito «Cisamba», substituindo a pronúncia do «Ki» pelo «Ci» ou «Tchi» e o «za» pelo «sa» que por força da lógica, captaria o som de «ça» português.

«Dombe-Grande», enquanto topónimo é expresso em língua portuguesa mas a região é habitada pelo povo Ndombe muito antes da penetração mercantil europeia (SANTOS 1893). Aquando do mercantilismo ocidental (DELGADO 1944) dividia-se o mesmo povo em duas realidades: Ndombe, ao sul da lagoa Civangulula e Kangengo ao norte, em direcção à Benguela. $\mathrm{Na}$ eventualidade de ser tradução directa das línguas locais Ndombe Inene para o português «Dombe-Grande», também não existiu antes da ocupação europeia (FELNER 1940). No presente momento a região é conhecida por dois topónimos: Dombe-Grande (MILHEIROS 1972), que se refere à língua portuguesa e Ndombe, quando designa a região nas línguas locais (GOMES 2007).

Tudo aponta para que Dombe-Grande tenha emergido pela eventual corrupção de Ndamba Inene que em línguas locais quer dizer «grande bacia hidrográfica», em função das cheias do interior e consequente dispersão do rio Kupololo durante o período das suas inundações (cf. GOMES op. cit.).

21 Da tradição oral local, sabe-se que um caçador de nome Ndombe, perseguindo elefantes a partir da Hañya, errou pela foz do rio Kupololo. Incapaz de levar de volta o mamífero abatido aí se terá alojado, fundando uma povoação que ficou com o seu nome (Id., ibidem). A irrelevância desta informação oral reside no facto de haver textos reproduzindo informações similares, que se referem às géneses toponímicas das estruturas políticas do Planalto Central.

Depreende-se que a presença de lagos, vales, hortos e ribeirinhos intermitentes, na bacia hidrográfica da foz do rio Kupololo têm facilitado a permanência das inundações e grandes cheias geralmente vindas do interior, e o próprio extensivo leito do rio, tudo isto, em língua local é designado por ndamba, melhor dito, ondamba (plural: olondamba) ou indamba (Id., ibidem).

Em termos lógicos, sustentar-se-ia o designativo Dombe-Grande enquanto topónimo, na razão de haver um Dombe-Pequeno, que, no entanto, nunca terá sido identificado, a não ser pela informação dada pela Enciclopédia Luso-Brasileira, que não podemos corroborar, na qual se escreve que «encontra-se na margem direita do rio Cavaco, ido pelo leste, ao longo do antigo caminho do comércio Ngangela». Consequentemente, segundo Ralph Delgado (1948), Dombe-Pequeno localiza-se ao longo da entrada da que é hoje designada comuna do Dombe-Grande, antes da travessia do rio Kupololo. Porém, instituições vocacionadas para o estudo e gestão cartográfica, nomeadamente o Instituto Geodésico e Cartográfico de Angola (IGCA) e o sector de Geografia do Instituto Superior de Ciências de Educação (ISCED) de Benguela, não confirmam ter havido localidade alguma com o topónimo de Dombe-Pequeno no espaço em epígrafe. Até que 
surjam outras informações e se projectem novos estudos, fica-se assim, unicamente, com o registo da Enciclopédia Luso-Brasileira.

Para o Mundombe, ndombe é um designativo que se utiliza para designar «coisas de cor preta, quer dizer escuro, preto, negro» (GOMES 2007):

a. $\quad$ Bagre (eponde ly'ondombe) muito consumido pela comunidade;

- Amendoim, isto é, jinguba (olongupa vy'ondombe) planta herbácea leguminosa (Arachys hypogaea) a qual é comum ser comida torrada, e que caracterizava o ambiente ecológico e económico local. A referida jinguba foi muito cultivada em tempos idos em paralelo ao milho, feijão, cará, café, tabaco, mandioca, bastante referenciados pelos comerciantes portugueses, que por ali fizeram as suas incursões comerciais (SANTOS 1890), e militares, durante a época de penetração e ocupação respectivamente, segundo Andrew Battel, ${ }^{28}$ citado por R. Delgado (1944).

- Touro sagrado (ongombe y'ondombe) que caracteriza a religião, o símbolo do poder social e económico na tradição local (MILHEIROS 1947; ESTERMANN 1944).

Em suma, o Mundombe designa-se a si próprio assim, eventualmente, não em função da raça a que pertence, pois, não se constatam conceitos rácicos nas línguas locais, mas, tendo em conta que ele é pertença de uma entidade etnolinguística que o identifica em plena consciência. Caracterizando-se a sua cultura a volta destes argumentos, não nos parece normal que façam uso de um etnónimo do seu subgrupo sem significado de carácter moral ou sociocultural em seu benefício. Assim, passa a designar o indivíduo não da região do Dombe-Grande mas do subgrupo do grupo etnolinguístico - o Mundombe - como sendo «a pessoa humana das coisas de cor preta» (GOMES 2007). Entretanto, em língua umbundu todos os naturais ou residentes do Dombe-Grande, sem discriminação, são Vandombe (singular: Undombe, Ndombe).

Sendo um étimo no singular, Ndombe (plural: Vandombe), é designativo de uma determinada e bem definida área sociocultural correspondente com um subgrupo da etnia Helelo, do qual se extrai um antropónimo singular e neutro «Mundombe», cujo prefixo «Mu», quer dizer «homem» ou «alma» em língua local, e na terminologia em si «Mundombe» passa a designar, «uma pessoa, um ser humano» do grupo etnolinguístico Helelo, particularmente do subgrupo Ndombe (GOMES op. cit.).

O contexto Ndombe (DIAS 1961) sugere que, parafraseando A. Almeida (1960: 107),

«[...] as culturas, qualquer que seja a latitude da terra, não são estacionárias, não cristalizam em limites hermeticamente fechados. Abertas às influências circunvizinhas, desenvolvem-se, crescem, alastram-se, invadem campos alheios, modificam outras culturas e também, por si próprias e isoladamente, se desenvolvem sem qualquer influência estranha».

A lógica da confusão, dos estudiosos da época colonial, justifica-se pelo facto de tratarse de um Dombe-Grande cujo complexo sociocultural é sincretizado, como é o Planalto Central de Angola, decorrente das acomodações de origem diversificada. Grandes transformações socioeconómicas, políticas e culturais aconteceram a partir de 1920 com a fundação da "Companhia do Assucar de Angola, S.A.» (sic) ${ }^{29}$ por um colono português conhecido por A. Souza C. Lara, cuja sede social se estabeleceu em Luanda com escritórios em Benguela e Lisboa. Sabe-se ter sido proprietário, de entre outros empreendimentos, da Fazenda Tentativa, localizada em Caxito, e da denominada Fazenda S. Francisco, localizada aqui no Dombe-Grande. Uma outra, reservada à produção de sisal, encontrava-se no Cubal e chamou-se Fazenda Marco de Canavezes. A elas se adicionou a empresa Sociedade de Recovagens no Lobito. Foi tudo nacionalizado 
por abandono dos seus proprietários no advento da independência de Angola em 1975; posteriormente, a Companhia passou a chamar-se Açucareira 4 de Fevereiro, tendo herdado por essa ocasião cerca de 2500 trabalhadores que, muitos anos mais tarde, em 1991, terão passado a condição de desempregados, em virtude da referida empresa ter entrado em estado de falência por falta de reposição de peças sobressalentes $e$ equipamentos de todo o tipo.

Hoje, cerca de um século depois, a região confrontou-se com êxodos populacionais do interior para a mão-de-obra barata, adicionada aos desterrados do conflito de ocupação colonial de 1961 a 1974, dos deslocados da guerra de 1975 a 1990, assim como os de 1991 a 2002. A esta data a região albergou perto de 100 mil habitantes dos 130.906 de todo o município da Baía Farta, dos quais 30\% reclamavam a pertença da sociocultura Ndombe. Do total geral, 20 mil falantes da língua umbundu eram, a partir de 1999, abordos no Luacho; enquanto epicentro da cultura Ndombe, o complexo sociocultural da região encontrava-se sincretizado de tal forma, que hoje já não é fácil destrinçar o endógeno do exógeno em função dos valores perdidos, recuperados e emprestados.

Além dos Ovimbundu do Wambu, Mbokoyo, Mbalundu, Viyè, Cisanji, ${ }^{30}$ Kakonda, Kalukembe, Ciyaka, ${ }^{31}$ da Hañya e dos Vacilenge, cujo conjunto já não se distinguem a olho nu, paralelamente aos Vacipungu ${ }^{32}$ e Vankhumbi, são localizáveis os falantes do conjunto das línguas Ngangela, particularmente, o Cokwe e Lwimbi, assim como também a do corredor do médio Kwanza, no caso concreto da língua kimbundu. 0 olukwandu (ESTERMANN 1949), língua falada pelos Vakwandu, obviamente não é muito ouvida, mas tem um grau de interferência considerável, particularmente a nível de instituições tradicionais endógenas, melhor dizendo, da cultura invísivel aos olhos de fora, da cultura mais profunda.

31 Aludimos que os Vakwandu (singular: Mukwandu), acabaram por tornar-se uma comunidade especificamente periférica, sendo constituídas por células socioculturais bastante homogéneas, isoladas, tendo sido estudadas por Charles Estermann (1944, 1949, 1951) com o etnónimo de Vakwisi (singular: Mukwisi), sendo assim designados pelos Vakuvale e pelos demais populações Helelo, que os mantêm persistentemente marginalizados em virtude dos seus hábitos, usos e costumes, sobretudo por estes terem o hábito de consumir peixe (ombisi), um tipo de alimento impeditivo de ser ingerido por aqueles; contrariamente, este designam-se a si próprios por Vakwambundya (singular: Ukwambundya), sendo integrantes do grupo etnolinguístico Mbundya.

32 Na tentativa de fuga dos ataques daqueles, dos quais são incluídos os Vandombe, os Vakwambundya têm adoptado as culturas dos vizinhos como estratégia de protecção em que os Ovimbundu servem de escudo (ESTERMANN 1961a). Em consequência disso, convivem repartidos entre os adaptativo-adaptáveis, sendo por isso chamados gratuitamente de Vakwandu (singular: Mukwandu), e os resistentes, que não adoptam os valores exóticos são rotulados de Vakwisi (singular: Mukwisi), causando embaraços aos estudiosos e colectores de dados na diferenciação dos dois grupos, por deixarem parecer a presença dos Vakwisi localizados nas plataformas das montanhas e ao longo dos vales intermitentes, diferentes dos Vakwandu dispersos pelos bairros do DombeGrande, monopolizando o mercado da medicina tradicional que dá hegemonia histórica de ser uma região depreciada por «feitiços».

Em suma, a história da localidade de Dombe-Grande é, deveras, mais antiga, tal como também é a do Ndombe, diferindo-se essas terminologias pelos factos seguintes: 
- Antes, do processo de penetração à ocupação ocidental em África, isto é, nas primeiras décadas do século XVII (GONZAGA 1963) já se conhecia o Ndombe, de acordo com a informação veiculada pelo marinheiro inglês Andrew Battell, citado por Ralph Delgado (op. cit.), com as histórias dos jacarés que continuam nos nossos dias (DELGADO 1944). De um assunto aparentemente mitológico, relacionado com as sociedades secretas, Augusto Serra Frazão (1946) demonstrou como os Europeus se preocuparam, tornandoo um problema tido em conta durante a Primeira Guerra Mundial, a par das incursões militares dos nativos do interior nas guerras de pacificação (PÉLISSIER 1986). Acerca do jacaré do Dombe-Grande muito se tem falado e é na mitologia onde se ajusta o enquadramento dos respectivos tabus. Entretanto, o uso da bexiga do fel deste réptil para fins medicinais e religiosos (ELIADE 2006), permitiu que fosse aproveitado para servir de antídoto na luta contra a penetração portuguesa e consequente ocupação colonial do início do século XX. Portanto, apesar de toda a preocupação manifestada pelos colonialistas portugueses por este último motivo, o jacaré continua no Kupololo entre o mito e a realidade.

a. Até à altura da independência de Angola, proclamada no dia 11 de Novembro de 1975, Dombe-Grande estava categorizada, por uma portaria colonial n.. 14.061 de 13 de Dezembro de 1965, publicada pelo Boletim Oficial n.․ 50, da mesma época, como um posto administrativo do então Concelho da Baía Farta; posteriormente, esse posto administrativo foi elevado a município adstrito ao Distrito de Benguela (MILHEIRO 1972), e esse distrito foi na actualidade elevado à categoria de província, constituindo uma das 18 províncias da República de Angola.

- Por volta de 1911, através de uma portaria do regimento colonial com o n. 832 de 1 de Agosto, o Dombe-Grande passou administrativamente a circunscrição civil, segundo o que diz o Boletim Oficial n. 31 (id., ibidem). Neste contexto, a fixação dos seus limites administrativos são oficializados por uma outra portaria com o n. 1062 , publicada pelo Boletim Oficial $n .052$ do respectivo ano.

- Desde 1913, enquanto regedoria, o Dombe-Grande, no seu todo territorial era constituída por nove administrações a saber: a actual sede, com o mesmo topónimo, Vissola, Cuporolo, Granja, Luacho, Boa Lembrança, Lussila, Muaningo e Munda. Por seu turno, o Luacho, ainda nesta época, dispõe de um porto na localidade do Cuio, hoje administrativamente independente à semelhança da Equimina e da Baía dos Elefantes (ANTONITO 1955).

- Portanto, é desde 1918, pela portaria colonial n.. 61 , datada de 11 de Março do mesmo ano e publicada pelo Boletim Oficial n.. 11, que o Dombe-Grande passa à categoria de Posto Civil.

- Segundo o processo, mais político que juridicamente dito, da transferência das estruturas político-administrativas da Angola colonial para a República Popular de Angola, registado entre 1976 a 1979, sob auspícios da comissão política executiva do Movimento Popular de Libertação de Angola (MPLA) na Província de Benguela, o Dombe-Grande ficou cartografado com a categoria de comuna, adstrita ao município da Baía Farta, a 43 metros de altitude e 80 quilómetros ao litoral sul da cidade de Benguela.

Assim, pode observar-se que o Dombe-Grande, tal como é descrito na História de Angola, continua oficialmente na mesma ordem quer toponímica, quer administrativa. A única diferença digna de registo é o facto de na língua local, os seus habitantes não reconhecerem a referida região como Dombe-Grande, que é um topónimo de base e origem colonial, mas, simplesmente, como Ndombe. 


\section{Conclusão}

Ao fim do presente trabalho podemos concluir o seguinte:

1. O problema da interpretação dos topónimos, antropónimos, etnónimos e zoónimos no contexto angolano é tão antigo quanto a sua história, e esta ainda não tem merecido a atenção que lhe é devida por parte dos investigadores e estudiosos sobre a realidade angolana, alguns dos quais preferem acomodar-se na reprodução dos materiais descritos pelos agentes coloniais, pelo que, o contexto do Dombe-Grande aqui escolhido é entendido no geral;

2. Os Vandombe (singular: Mundombe) não são parte integrante do grupo etnolinguístico Ovimbundu; no entanto, pelas razões apontadas, adoptaram e adaptaram-se a língua umbundu, que lhes serve de comunicação em primeira instância, como acontece com todos os outros grupos localizados na periferia do complexo sociocultural dominado pela língua umbundu. É que, hegemónica e dinâmica como é de facto a língua umbundu, a presença massiva dos Ovimbundu impôs aos grupos minoritários a adopção desta língua para a sobrevivência dos demais. A língua umbundu serve assim de língua franca para todos os intervenientes nesta vasta região sociocultural;

3. A penetração dos valores ovimbundu no litoral centro-sul de Angola está relacionada com a história da fundação dos estados do Planalto Central, particularmente o Viyè, fundamentado pelos Vankhumbi e a fundação da colónia portuguesa de Benguela no século XVII;

4. É apenas com o estudo dos conceitos-chave do léxico institucional endógeno, que se pode perceber o grau de influência de uma sociocultura dentro de outra, pelo que o estudo da História de Angola tem que passar necessariamente por uma abordagem socioantropológica, que poderá ajudar a procurar e reunir dados mais fiáveis e sustentáveis sobre a realidade local à luz da história.

\section{BIBLIOGRAFIA}

ALMEIDA António de et al., 1960, Estudos sobre etnologia do ultramar português. Lisboa, Junta de Investigações do Ultramar, vol. I [«Estudos, ensaios e documentos»; 81].

ALTUNA Padre Raul Ruiz de Asúa, 1993 (2. edição), Cultura tradicional Bantu. Apresentação de Dom Eduardo André Muaca; prefácio de João da Rocha Páris. Luanda, Secretariado Arquidiocesano de Pastoral.

ALVES Padre Albino, 1951, Dicionário etimológico Bundo-Português, 2 volumes. Ilustrado com muitos milhares de exemplos, entre os quais 2.000 provérbios indígenas. Lisboa, Tipografia Silvas.

ANTONITO [António Coxito Granado], 1955 (3. a edição), Dicionário corográfico-comercial de Angola. Inclui o mapa-esboço geral das estradas e terras de Angola, com os novos distritos e povoações. Luanda, Edições Antonito.

APARÍCIO Maria Alexandra, 1994, «Dombe Grande. A implantação dos dízimos e suas consequências na região: Os conflitos militares 1852-1859», Fontes \& Estudos. Revista do Arquivo Histórico Nacional (Luanda), n. 1, Novembro, pp. 49-61. 
BASTOS Augusto Tadeu Pereira, 1902, Traços geraes sobre a etnographia do Distrito de Benguela. Lisboa, Sociedade de Geographia de Lisboa.

CARDOSO Carlos Lopes, 1963, «Do uso da “cegonha” no Distrito de Moçâmedes». Luanda, Instituto de Investigação Científica de Angola.

CARDOSO Carlos Lopes, 1966, Olumbali do Distrito de Moçâmedes. Achegas para o seu estudo. Luanda; Porto, Imprensa Portuguesa.

CARVALHO Ruy Duarte de, 1997, A câmara, a escrita e a coisa dita... Fitas, textos e palestras. Luanda, Instituto Nacional do Livro e do Disco [«Estudos e documentos. Ensaio»; 16].

CARVALHO Ruy Duarte de, 1997, Aviso à navegação. Olhar sucinto e preliminar sobre os pastores kuvale da província do Namibe com um relance sobre as outras sociedades agropastoris do Sudoeste de Angola. Luanda, Instituto Nacional do Livro e do Disco [«Estudos e documentos. Ensaio»; 22].

DELGADO Ralph, 1948, História de Angola. Primeiro e segundos períodos de 1482 a 1648, vol. I. Benguela, Edição da Tipografia do Jornal de Benguela.

DELGADO Ralph, 1948, História de Angola. Primeiro e segundos períodos de 1482 a 1648, vol. II. Benguela, Edição da Tipografia do Jornal de Benguela.

DELGADO Ralph, 1944, Ao Sul do Cuanza. Ocupação e aproveitamento do antigo reino de Benguela, vol. I. Lisboa, Imprensa Beleza.

DELGADO Ralph, 1944, Ao Sul do Cuanza. Ocupação e aproveitamento do antigo reino de Benguela, vol. II. Lisboa, Imprensa Beleza.

DIAS Jorge, 1961, Ensaios etnológicos. Lisboa, Junta de Investigações do Ultramar — Centro de Estudos Políticos e Sociais [«Estudos de Ciências Políticas e Sociais»; 52].

DINIZ José de Oliveira Ferreira, 1915, Etnologia dos povos de Angola, tomo I. Luanda, Secretaria dos Negócios Indígenas do Governo Geral da Província de Angola; Imprensa Nacional de Angola.

DUFF Padre Frederico, 1945a, «A circuncisão dos Vankhumbi», Portugal em África. Revista de cultura missionária (Lisboa), $2^{\text {a }}$ série, vol. II, ano I, pp. 84-91.

DUFF Padre Frederico, 1945b, «A nubilidade dos Vankhumbi», Portugal em África. Revista de cultura missionária (Lisboa), 2. a série, vol. II, ano IV, pp. 293-297.

ELIADE Mircea, 2006, O sagrado e o profano. A essência das religiões. Tradução de Rogério Fernandes. Lisboa, Edição Livros do Brasil [«Vida e Cultura»].

ELIOT T. S., 1965, Notas para a definição da Cultura. Tradução de Fernando de Castro Ferro. Rio de Janeiro, Zahar Editores.

Enciclopédia Luso-Brasileira, 1963, Lisboa, Editorial Verbo.

ESTERMANN Padre Charles, 1960a (2. a edição corrigida), Etnografia do Sudoeste de Angola. Os povos não-Bantos e o grupo étnico dos Ambós, Vol. I. Lisboa, Junta de Investigações do Ultramar [«Memórias: Série Antropológicas e Etnológicas»; IV].

ESTERMANN Padre Charles, 1960b, «Os Ba-Nhaneka e os Ba-Kumbi no deserto de Moçâmedes», Boletim Cultural do Museu de Angola (Luanda), n. ำ 1 e 2, pp. 95-109 e 102-120.

ESTERMANN Padre Charles, 1951a, «O problema da diferenciação étnica em Angola (adaptação de uma palestra radiofónica», Mensário Administrativo. Publicação de assuntos de interesse colonial (Luanda), n.․ 43-44, Março-Abril, pp. 11-14. 
ESTERMANN Padre Charles, 1951b, «Os "Vatwa"», Mensário Administrativo. Publicação de assuntos de interesse colonial (Luanda), n. ${ }^{\circ}$ 49-50, Setembro-Outubro, pp. 51-54.

ESTERMANN Padre Charles, 1949, «A etnologia angolana em três livros recentes», Portugal em África. Revista de cultura missionária (Lisboa), ano II, 2. a série, vol. VI, pp. 65-74.

ESTERMANN Padre Charles, 1945, «A festa da puberdade em algumas tribos de Angola meridional», Portugal em África. Revista de cultura missionária, (Lisboa), vol. II, 2. érie, ano I, pp. 45-51.

ESTERMANN Padre Charles, 1941-1942, «La fête de puberté dans quelques tribus de l'Angola méridional», Bulletin de la Société Neuchâteloise de Géographie (Neuchâtel), tomo XLVIII, pp. 128-141.

FELNER Alfredo de Albuquerque, 1940, Angola. Apontamentos sobre a colonização dos planaltos e litoral do Sul de Angola. Extraídos de documentos históricos por Alfredo de Albuquerque Felner, 3 volumes. Lisboa, Agência Geral das Colónias.

FRAZÃo Augusto Serra, 1946, Associações secretas entre os indígenas de Angola. Breves apontamentos sobre a provável existência de associações secretas e práticas ocultistas entre as populações gentílicas de Angola. Estudos etnográficos dos povos de Angola, II. Prefácio de Norton de Matos. Lisboa, Editora Marítimo-Colonial, Lda.

GOMES Armindo Jaime, 2007, As civilizações lacustres das margens do Kupololo. Prefácio de Maria Alice dos Santos Cabral. Benguela, KAT — Empreendimentos \& Consultoria [«Estudos»; 2].

GONZAGA Norberto, s.d. [1963?], História de Angola 1482-1963. Luanda, Centro de Informação e Turismo de Angola — Fundo de Turismo e Publicidade.

GRAÇAS Jr. Manuel Coelho, 1948, «Do Curoca a caminho da voz do Cunene», Mensário Administrativo. Publicação de assuntos de interesse colonial (Luanda), n.ำ 5aneiro, pp. 37-40. Grande Enciclopédia Luso-Brasileira, 40 volumes, Lisboa, Rio de Janeiro.

Grand Larousse Encyclopédique en dix volumes, 1960-1964, Paris, Librairie Larousse.

GROMIKO A.; ISMAGUILOVA R.; KOBICHANOV Iú., et al., 1987, As religiões da África: Tradicionais e sincréticas. Tradução de G. Mélnikov; revisão de Paula Costa do Campo Milakova. Moscovo, Edições Progresso.

LEMOS Alberto de, 1929, História de Angola. Luanda, Imprensa Nacional de Angola.

LEMOS Alberto de, 1932, História de Angola. Primeiro volume 1482 a 1684. Lisboa, Oficina Gráfica, Lda.

LIMA G. A. Mesquitela, 1964, A Etnografia Angolana. Considerações acerca da sua problemática actual. Luanda, Publicações do Museu de Angola; Imprensa Nacional de Angola.

MACHADO Carlos Roma, 1918, «Colonização do Planalto da Huíla e de Mossâmedes: Seu desenvolvimento agrícola e industrial», Boletim da Sociedade de Geographia de Lisboa (Lisboa), série 36, n. ${ }^{\circ}$ 10-20, pp. 267-309.

MANZAMBI Vuvu Fernando, 1993, «A identidade cultural numa sociedade pluriétnica», Jornal de Angola (Luanda), 28 de Novembro, p. 16.

MELO Rosa, 1990, A instituição da efiko nos Nyaneka-Nkhumbi. Trabalho efectuado para a obtenção do grau de licenciatura em Ciências de Educação. Lubango, Instituto Superior de Ciências da Educação da Huíla.

MILHEIROS Mário, 1972, Índice histórico-corográfico de Angola. Luanda, Instituto de Investigação Científica de Angola. 
MILHEIROS Mário, 1947, «As religiões nas tribos angolanas», Mensário Administrativo. Publicação de assuntos de interesse colonial (Luanda), n.. 4, Dezembro, pp. 15-16.

MORAIS A., 1952 (10. edição), Grande dicionário da língua portuguesa, vol. IV. Lisboa, Editora Confluência.

NETO Maria da Conceição, 1997, «Entre a tradição e a modernidade: Os Ovimbundu do Planalto Central a luz da história», Ngola. Revista de Estudos Sociais (Luanda), da Associação de Antropólogos e Sociólogos de Angola, vol. I, n.․1, pp. 193-215.

NETO Maria da Conceição, 1994, «Entre colonos e “quimbares" no extremo sul de Angola», Austral. Revista de Bordo da TAAG (Luanda), n.. 8, pp. 35-53.

NETO Maria da Conceição (org.), 1993, Texto de apoio para o domínio do vocabulário de parentesco, no Curso de História de Angola do ano lectivo 1992-1993, orientado pela Professora Maria da Conceição Neto. Luanda, ISCED — Instituto Superior de Ciências da Educação, 8p. [policopiado].

NOGUEIRA A. F., s.d. (5. e edição), Olun Kumbi, dialecto do grupo On Bundu que se fala no Distrito de Moçâmedes. Lubango, Huíla, Edição do autor.

NOGUEIRA A. F.,1885, «Àcerca do Lu'n Kwbi», Boletim da Sociedade de Geographia de Lisboa (Lisboa), 5. aㅗ série, n. ${ }^{\circ} 7$.

NOGUEIRA A. F.,1877, «Os Banhaneca e os Bankumbi (África Central), a propósito do livro de Sir John Lubbock: "As origens da civilização"», Boletim da Sociedade de Geographia de Lisboa (Lisboa), 1." série.

PÉLISSIER René, 1986, História das campanhas de Angola. Resistências e revoltas (1845-1941), 2 volumes. Lisboa, Editorial Estampa [«Imprensa universitária»; 50 e 51].

REDINHA José, 1975, Etnias e Culturas de Angola. Luanda, Instituto de Investigação Científica de Angola e Banco de Angola.

REDINHA José, 1973, Etnografia e etnologia de Angola. Luanda, Instituto de Investigação Científica de Angola [«Bibliografias temáticas»; 20].

REDINHA José, 1970, «Angola - Etnias e Culturas (esboço)», Trabalho (Luanda), n. 29, 1.ำ

trimestre, pp. 113-146.

REDINHA José, 1961, Distribuição étnica de Angola. Introdução, registo étnico, mapa. Luanda, Edição do Centro de Informação e Turismo de Angola [Separata do Mensário Administrativo. Publicação de assuntos de interesse colonial (Luanda), n.․ 167-172, Junho-Dezembro de 1961]

RAVENSTEIN E. G., 1901, The strange adventure of Andrew Battel of Leigh, in Angola and the adjoining regions. Reprinted from «Purchas his Pilgrimes», edited, with notes and a concise History of Kongo and Angola, by E. G. Ravenstein. Londres, The Hakluyt Society, 210p. [Reprinted from Samuel Purchas, Hakluytus posthumus or Purchas, his Pilgrims, containing a history of the world in sea voyages and land travels by Englishman (Londres, 1625) and from Samuel Purchas, His Pilgrimage (London, 1613)].

RIBAS Tomás, 1977, Etnografia (1). Lisboa, FAOJ — Fundo de Apoio aos Organismos Juvenis [«Cadernos FAOJ», n. 5 , série B].

ROQUE António Bernardino, 1905, "Contribuição para o estudo do planalto de Mossamedes», Boletim da Sociedade de Geographia Lisboa (Lisboa), 23.․ㅗ série, n.o 6, pp. 197-282.

SANTOS Ana de Sousa, 1963, Catálogo da exposição de miniaturas angolanas. Fotografias de Sousa Viana. Luanda, Instituto de Investigação Científica de Angola. 
SANTOS Ana de Sousa, 1965, Exposição «Miniaturas Angolanas» de Ana de Sousa Santos: Catálogo. Lisboa, Câmara Municipal.

SANTOS Eduardo dos, 1969, «Religiões de Angola». Lisboa, Junta de Investigações do Ultramar [«Estudos ultramarinos»; 3].

SANTOS Ignácio dos, 1890, «O comércio no Planalto de Moçâmedes», Portugal em África. Revista de interesse missionário (Lisboa), vol. 5, n. 59, pp. 110-126.

SANTOS Ignácio dos, 1893, «O modo de viver dos pretos no planalto de Moçãmedes», Portugal em África. Revista de interesse missionário (Lisboa), vol. 5, n.ำ 60, Dezembro, pp. 77-78.

SOROMENHO Castro, 1944, «Mucanda I. A origem da circuncisão», Revista Mundo Português (Lisboa), vol. VII, s/n., pp. 40-52.

TORRES Manuel Júlio de Mendonça, 1950, O Distrito de Moçâmedes, nas fases de origem e da primeira organização, 1485-1859. Lisboa, Agência Geral das Colónias — Divisão de Publicações e Biblioteca.

\section{NOTAS}

1. Trata-se, por um lado, do designativo de indivíduos que integram o grupo etnolinguístico Ndombe (plural: Vandombe), e, por outro lado, da designação de todos os habitantes e naturais do chamado Dombe-Grande.

2. Leia-se Vatchiavikua.

3. Das quais ressaltamos a obra 0 poder da autoridade tradicional em Benguela [www.buala.org.].

4. Vacilenge (singular: Mucilenge). Leia-se Vatchilengue, Mutchilenge.

5. Olucilenge é a língua falada pelos Vacilenge (singular: Mucilenge), uma variante local umbundu, do grupo étnico Ovimbundu, sendo mais conhecidos no âmbito colonial por Quilengues.

6. Leia-se tchilengue.

7. No catálogo da exposição de Miniaturas angolanas. Ana de Sousa Santos foi uma experiente investigadora angolana que trabalhou para a Divisão de Etnologia e Etnografia do Instituto de Investigação Científica de Angola (IICA), tendo-se dedicado à pesquisa etnográfica, principalmente na região de Luanda, cujos materiais estão publicados por essa instituição científica colonial.

8. Leia-se Olutchilengue.

9. Cimbundu (plural: Ovimbundu), um membro da comunidade. Leia-se Tchimbundu.

10. Leia-se Tchilengue.

11. Tal depreciativo ainda hoje é ouvido na província do Namibe.

12. Tema do nosso trabalho de fim de ano para a graduação em História no Instituto Superior de Ciências da Educação (ISCED) de Luanda.

13. Leia-se Otchimbundu.

14. Dito em língua local Lusila.

15. Isto é, Kamukuyu, grafado a partir da língua local.

16. Isto é, Vimbala, grafado assim com base na língua local.

17. Dito em língua local Katombela.

18. Dito em língua local Mbwelo.

19. Dito em língua local Njila Hulu.

20. Dito em língua local Vityanva.

21. Catumbela oficialmente.

22. Cunene oficialmente.

23. Leia-se Tchipola. 
24. Localizado na cidade do Namibe.

25. Leia-se Tchitôto.

26. Localizado na cidade do Namibe.

27. Acerca deste assunto, cf. Grande Enciclopédia Luso-Brasileira.

28. Viajante inglês que terá passado pelo Dombe Grande (1589-1614) [Nota do Autor]. Acerca deste personagem consulte, por exemplo, E. G. Ravenstein (1901) [Nota do Editor].

29. <http://restosdecoleccao.blogspot.com/2013/04/companhia-do-assucar-deangola.

htm>.

30. Leia-se Tchissanji.

31. Leia-se Tchiaca.

32. Leia-se Vatchipungo.

\section{RESUMOS}

O presente texto resulta de um conjunto de dados e materiais recolhidos no período de 1997 a 2007, na localidade de Dombe-Grande, na província de Benguela, em Angola, aquando da estadia aí efectuada ao serviço de um operador não estatal, aplicando métodos de desenvolvimento comunitário, com particular incidência os sociológicos, históricos e antropológicos. Na altura, julgava-se imperativo conhecer a realidade envolvente para uma actuação participativa. Identificou-se o contexto começando por se estudar os aspectos relativos à toponímia, etnonímia, antroponímia e zoonímia, por se acreditar que os mesmos constituíam os pontos-chave para a interpretação das dinâmicas socioculturais endógenas, aproveitando delas a elaboração de instrumentos de trabalho que se exigiam. Através dos dados resultantes da oralidade, foi-nos possível esclarecer que os materiais e informações produzidos ainda na época colonial e que são hoje de uso frequente, que defendem que o Mundombe é umbundu, não correspondem à realidade. Consequentemente, informação contrária igualmente recolhida nesse mesmo contexto, mostra não ser do todo desconhecida, uma vez que vários grupos Ndombe convergem na área de localização e falam a língua umbundu, não obstante diferenciarem em termos identitários.

This paper is the result of a set of data and materials collected in the period of 1997 to 2007 in the town of Dombe Grande in the province of Benguela, Angola, during the stay we made there service on behalf of a non-State operator, applying community development methods, particularly sociological, historical and anthropological. At the time, we thought it was imperative to know the surrounding reality for participatory action. It was identified the starting context by studying aspects of the names related with the place and peoples culture. We believed that those names constitute key points for the interpretation of endogenous socio-cultural dynamics, taking advantage of them to draw up the work tools required. Through evidence from orality, we were able to clarify that materials and information generated during the colonial period are frequently used today, as those materials and information argue that Mundombe is umbundu, that not correspond to the reality. Contrary information was also collected in the same context, which is not entirely unknown, since various groups Ndombe from the same location, that speak the language umbundu, nevertheless differentiate in terms of identity. 


\section{ÍNDICE}

Keywords: Dombe-Grande, Benguela, Ndombe, Mundombe, olundombe, Ovimbundu, Umbundu, socioculture

Palavras-chave: antroponímia, etnonímia, toponímia, zoonímia, Dombe-Grande, Benguela, Ndombe, Mundombe, olundombe, Ovimbundu, umbundu, sociocultura

\section{AUTOR}

\section{ARMINDO JAIME GOMES}

arjago_kat@yahoo.com.br cacul.k@gmail.com

Docente da cadeira de História de Angola na Academia Militar do Exército (Benguela).

É mestre em Administração escolar (2010) pela Universidade de Évora, Portugal e licenciado em Ensino da História (1996) pelo Instituto Superior de Ciências da Educação (ISCED) do Lubango, Huíla. Actualmente é docente da cadeira de História de Angola na Academia Militar do Exército, em Benguela. No período de 1997 a 2007, foi director da Antena e Coordenador de projectos em Benguela da Acção para o Desenvolvimento Rural e Ambiente (ADRA) e docente da cadeira de História de Angola, de Didáctica especial da História e prática docente no Instituto Superior de Ciências da Educação (ISCED) de Benguela; entre 2008 e 2010, foi consultor independente para questões da área da Sociedade Civil (actores não-estatais, Convenção de Cotonou) para a CEE Comunidade Económica Europeia); no período entre 2010 e 2013 foi Administrador/Director da Sociedade KAT - Empreendimentos \& Consultorias, Lda., em Benguela e docente das cadeiras de Psicologia intercultural e Métodos e técnicas de análise sociológica no Instituto Superior Pedagógico Jean Piaget (Benguela); no período de 2013-2014 foi docente de História de Angola e outras disciplinas no Instituto Superior Politécnico Sol Nascente, na cidade do Huambo (província do Huambo). Enquanto investigador publicou entre outros os materiais seguintes: Epata L'Usoma. Apontamentos etno-históricos Ovimbundu (2000), Os Sobas. Apontamentos etnohistóricos Ovimbundu de Benguela (2003), As civilizações lacustres nas margens do Kupololo. Ensaio etno-histórico sobre Benguela (2007). Além das múltiplas funções de investigador, docente e consultor, é escritor membro da União dos Escritores Angolanos (UEA), onde assina com o anagrama Arjago, tendo publicado: Crepúsculo matutino. Poesia (1990), Noites por dia. Poesia (1998), Prémio Literário António Jacinto. Figura na obra colectiva Todos os sonhos. Antologia da poesia moderna, com o qual a UEA comemorou 30 anos de literatura em Angola. 